\title{
Gamma Irradiation to Sterilize Active Ingredients, Consumer Foodstuffs and Beverages in Bangladesh
}

\author{
Hasan M. Zahid (Corresponding Author) \\ Institute of Radiation \& Polymer Technology (IRPT), Atomic Energy Research Establishment (AERE), \\ Ganakbari, Savar, Dhaka-1349 \\ Email: zahidhasan.bmb@yahoo.com
}

\section{Mohammad Zahirul Islam Mollah}

Institute of Radiation \& Polymer Technology (IRPT), Atomic Energy Research Establishment (AERE), Ganakbari, Savar, Dhaka-1349

\author{
Ruhul A Khan \\ Institute of Radiation \& Polymer Technology (IRPT), Atomic Energy Research Establishment \\ (AERE), Ganakbari, Savar, Dhaka-1349
}

\author{
Article History \\ Received: 24 January, 2022 \\ Revised: 21 February, 2022 \\ Accepted: 1 March, 2022 \\ Published: 4 March, 2022 \\ Copyright (c) 2022 ARPG \& \\ Author \\ This work is licensed under \\ the Creative Commons \\ Attribution International \\ (c) (1) CC BY: Creative \\ Commons Attribution \\ License 4.0
}

\begin{abstract}
Nowadays, the utilization of gamma irradiation (e.g., Cobalt-60 source) to sterilize different materials have been increasing enormously. As terminal sterilization, gamma irradiation is being used popularly to sterilize different materials throughout Bangladesh. Compare to other conventional methods of sterilization (e.g., alpha, beta, other chemicals), this method is highly applicable for its well acceptance in the world. It has high penetration power with the short wave lengths, isothermal characteristics for its negligible rise in the temperature, no contact with any toxic chemicals without having any unirradiated portion. In this process, the assurance level of the sterility of product is far better than other aseptic processing. The chemical bonds in the microbes are broken to produce reactive oxygen species (ROS) by gamma irradiation, and attack DNA/RNA of microbes for killing. The mutations in the genetic materials (DNA/RNA) of microbes are usually happened through gamma irradiation and consequently restrict the cellular division of microbes. This characteristic of gamma ray is mostly applicable in the commercial purposes. This review discusses the general applications of gamma irradiation to the broaden arena of different materials (active pharmaceutical ingredients, consumer products, beverages etc.). A summarized description of materials those are irradiated using Cobalt-60 source in Bangladesh, in particular, at the Institute of Radiation \& Polymer Technology (IRPT), Bangladesh Atomic Energy Commission, is described here. The information may further assist to enhance the dissemination of the applicability of gamma irradiation throughout Bangladesh.
\end{abstract}

Keywords: Gamma irradiation; Pharmaceutical products; Consumer foodstuffs; Beverages.

\section{Introduction}

The term radiation comes from the phenomenon of waves emitting from a source. Radiation can be happened through the emission or transmission of energy in the form of waves or particles that passes through the various spaces or media $[1,2]$. The available types of radiation are electromagnetic radiation, e.g., gamma $(\gamma)$ radiation, radio waves, microwaves, infrared, visible light, ultraviolet, x-rays; particle radiation, e.g., alpha $(\alpha)$, beta $(\beta)$, proton and neutron radiation; acoustic radiation, e.g., ultrasound; gravitational radiation, radiation that can be formed as the gravitational waves [3-5]. Radiation technology presents a very large scope for utilization and commercial uses in the versatile area. This technology is being favorably considered for different applications, for instances, sterilization of pharmaceutical/ medical products, preservation of food by controlling the shelf-life and the removal of microbial and insect pests. Based on the energy, radiation is usually categorized as ionizing or non-ionizing. Ionizing radiation carries more than $10 \mathrm{eV}$, that is adequate to ionize atoms and molecules. A common source of ionizing radiation is radioactive materials that emit $\alpha, \beta$, or $\gamma$ ray, comprising helium nuclei, electrons, positrons, and photons, respectively [6]. Particle radiation or cosmic rays almost invariably carries enough energy to be ionizing [7]. Thus ionizing radiation is fully different from particle and electromagnetic radiation in term of its detrimental effects in the biological damages [8].

Among different sterilization methods, the most effective and promising method of sterilization is gamma irradiation. Gamma radiation consists of photons with a short wave length, less than $3 \times 10^{-11}$ meters [9]. Alpha and beta particles interact with other atoms by the electric charge, whereas gamma radiation penetrates much rapidly than the alpha or beta radiation due to the absence of any electrical charge. So, gamma radiation can penetrate intensely into the material, and consequently cause the formation of reactive oxygen species (ROS) followed by the breakage of chemical bonds in the molecules. These are the general properties of gamma irradiation those can alter the large biological molecules [10]. The profound penetration is one of the biggest advantages of gamma irradiation. Compare to other conventional methods of sterilization gamma irradiation has the following advantages, (i) the competence of penetration of photon that allows sterilization of materials at different concentrations, (ii) not required 
to add extra heat or moisture (vi) does not yield any residue (v) more convenient to report the sterility assurance level $\left(\mathrm{SAL}, 10^{-6}\right)$ (vi) mostly applicable in the terminal sterilization. The effect of gamma radiation can be restricted by a sufficiently thick or dense layer of materials, where the stopping power of the materials per given area depends mostly on the total mass [11].

Bangladesh Atomic Energy Commission (BAEC) has taken the radiation processing programmes in a broaden area right from its inception. This article describes the application of gamma radiation carried out through various research groups in BAEC mainly using Cobalt-60 gamma source. Here, we give a general view of the applications of gamma radiation conducted particularly at the Institute of Radiation and Polymer Technology (IRPT). This review highlights the application of gamma sterilization to a broad spectrum of pharmaceutical materials, consumer foodstuffs, beverages etc. conducted at IRPT in BAEC.

\section{Gamma Radiation/Source}

The gamma radiations are transmitted from the radioactive nuclide as a charge less molecule because in this process no change in atomic number/mass is happened. For instances, Technetium- $99 \mathrm{~m}$ is decayed in the form of gamma radiation [12]. The energy range in the gamma ray is from 104 to $107 \mathrm{eV}$ [13]. They are frequently emitted as a part of a nuclear reaction, when an atomic nucleus remains in an excited condition, they can also be emitted following alpha-particle, beta-particle decay, or orbital electron capture, if the daughter nuclide is stayed in an excited state [14]. Gamma radiation passes through living materials very smoothly, and travels at a speed like the speed of light. In the radionuclide decay processes, in an excited state the nuclide either falls directly to the ground state or in the lower energy states through the dissipation of energy as gamma ray. A nuclide in an excited energy state is referred to as a nuclear isomer, and the transition from a higher to a lower energy state is referred to as isomeric transition. The energy of a gamma ray, E $\gamma$, can be stated as the difference in energy states of the nuclear isomers: $\mathrm{E} \gamma=\mathrm{h} v=\mathrm{E} 1-\mathrm{E} 2$; $\mathrm{h} v$ is the energy of electromagnetic radiation, and E1 and E2 are the nuclear isomers energy levels [13]. There are three units available to measure radiation, e.g., giga becquerel (GBq), gray (Gy), and roentgen $(R)$ [15]. There are three different categories of natural gamma radiation sources: (i) potassium (40K) with a half-life of $1.3 \times 109$ years, uranium-238 (238U) with a half-life of $4.4 \times 109$ years, uranium-235 (238U) with a halflife of $7.1 \times 108$ years and thorium $(232 \mathrm{Th})$ with a half-life of $1.4 \times 1010$ years, (ii) radioactive isotopes from the first group, those have half-lives ranging from small fractions of a second to 104 to 105 years, (iii) the generation of isotopes from the first group created by external causes, such as the interaction of cosmic rays with the earth and atmosphere [16].

\section{Applications of Gamma Radiation}

Gamma irradiation is the most effective technology in the elimination of pathogenic microorganisms without altering the nutritional values of food [17]. The authenticity of irradiated food has been permitted by the World Health Organization (WHO), the Food and Agriculture Organization (FAO), the International Atomic Energy Agency (IAEA), and the US Food and Drug Administration (FDA) [18]. For instance, twenty different food items are approved to be treated in Korea by irradiation up to $10 \mathrm{kGy}$ for the purpose of inhibition of sprouting, destruction of food borne insects and parasites, delay of physiological ripening, an extension of shelf life, or improvement of food qualities [19]. As an electromagnetic radiation with the shortest wavelength and highest energy, gamma ray has vast application in the different aspects. Gamma irradiation is a well established technique for polymerization and to enhance the electrical conductivity of the polymers [20]. The most important application of gamma radiation is in the clinical sectors are: dressings, tubes, catheters, syringes, infusions assemblies and implants etc. [21]. Gamma radiation is using for decontaminating foods [22], and is used in the treatment of a different types of cancers [23].

\subsection{Radiation Sterilization at IRPT}

IRPT is conducting radiation sterilization of different materials including active pharmaceutical ingredients, consumer foodstuffs, beverages etc. through the Cobalt-60 gamma source since 2010. Following the safety and securities provided by IAEA, the samples are usually received from the different pharmaceutical companies (e.g., Square Food \& Beverages Ltd., Khan \& Brothers Company, Raiyan Trade etc.) at IRPT. 350 kCi gamma source has been used in the commercial irradiation services to different purposes such as sterilization of pharmaceuticals, decontamination of medical products, microbial load reduction of food products etc. It can also be utilized in the pest control, the inhibition of germination of onion, potato etc. and properties modification of materials including rubber, polymers for research and development purposes [24]. Around 25 companies have been involved to get this service from IRPT. The major irradiated food products at IRPT are spices, e.g., chili, turmeric, coriander, cumin, leaf, seasoning spices, pet food etc. The dose applied for microbial load reduction of spices is $6 \mathrm{kGy}$. But some other food products may require 8-10 kGy. Different medical items are also being irradiated for sterilization purpose such as surgical gloves, syringe, infusion set, plastic container, tube etc. For complete sterilization, generally $25 \mathrm{kGy}$ is applied. In this article the data of last three years are analyzed, Table-1 shows the company-wise irradiated products in the last three years (2019-2021). 


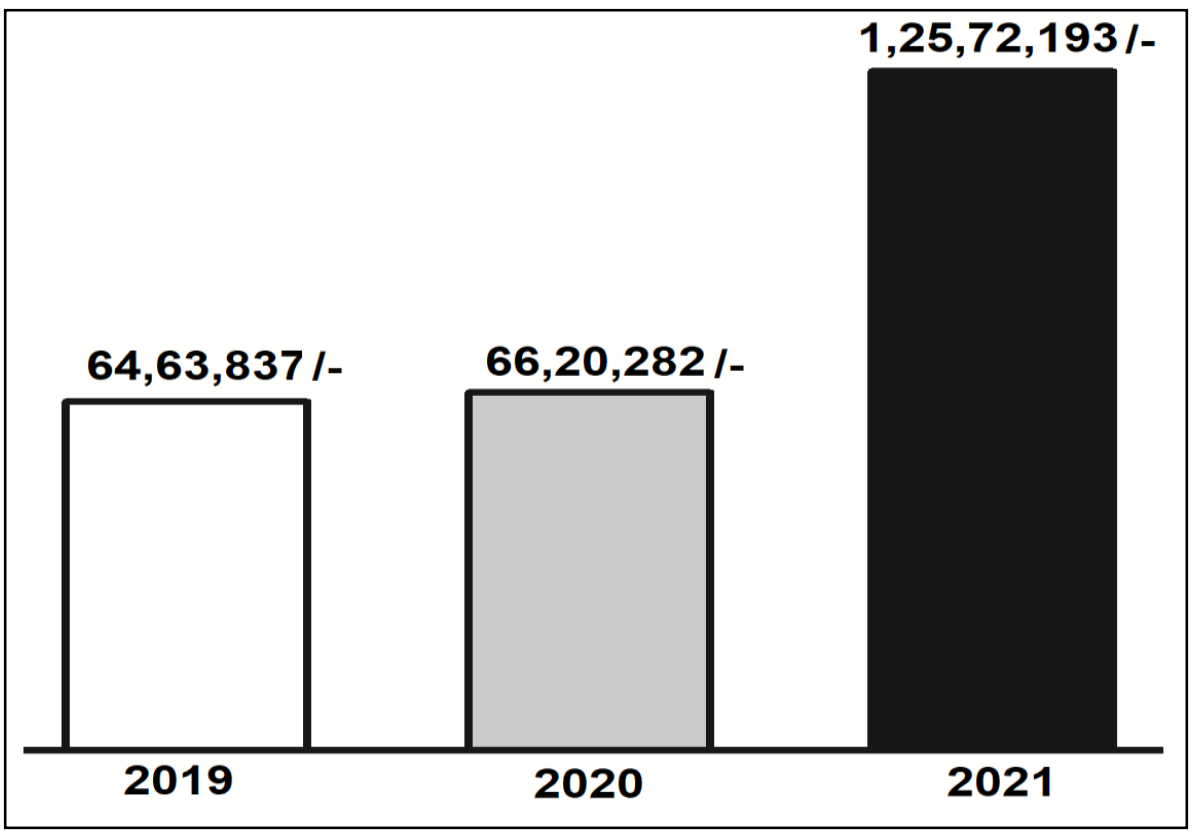

Figure-1. The record of the earning money in last three years by the gamma irradiation at IRPT

Square Food and Beverage Ltd. is one of the leading companies that is taking the service in a regular basis to sterilize various types of spices. In 2019-2021, major part of the currency was added in the revenue budget of government through the sterilization of spices of this company from IRPT. Due to the pandemic of COVID-19, in Mar-May'2020 the services were temporarily stopped, so the earning in 2020 was not significantly increased compare to the values of 2019 (Figure-1). Pet food is a very appealing product that is mostly sterilized in this tenure, almost 10 different companies (such as DDRM agro food Ltd., Aman Enterprise, Raiyan Trade) were involved.

Table-1. The list of products of the different companies in Bangladesh irradiated by gamma ray in the last three years (2019-2021) at IRPT

\begin{tabular}{l|l|l}
\hline SI No. & Name of the consumer/companies & Product Descriptions \\
\hline 1 & Kemico pharmaceuticals Ltd & Eye drops \\
\hline 2 & Pran Agro Ltd. & Spice \\
\hline 3. & Pran Food Ltd. & Food \\
\hline 3 & Square Food and Beverage Ltd. & Spice \\
\hline 4 & Green Speel & Dried fish \\
\hline 5 & DDRM agro food Ltd. & Pet food \\
\hline 6 & Natural pet foods & Pet food \\
\hline 7 & Aman Enterprise & Pet food \\
\hline 8 & Ziska Pharma Ltd. & Z-lodocaine jelly \\
\hline 9 & M. M International & Pet food \\
\hline 10 & Shibu Enterprise & Dressing materials \\
\hline 11 & Advanced Chemicals Industries (ACI) & Pharma consumer products \\
\hline 12 & Raiyan trade & Pet food \\
\hline 13 & N. K. Sea Food International & Pet food \\
\hline 14 & M. R. Trading Corporation & Herbal powder \\
\hline 15 & J. C. Trading Company & Pet food \\
\hline 16 & Khan \& brothers company & Eye drop \\
\hline 17 & GB Medical Ltd. & Surgical gloves \\
\hline 18 & Bangladesh Institute of Nuclear Agriculture & Pet soil dust \\
\hline 19 & EINA) & \\
\hline 20 & SurgMate & Pet food \\
\hline 21 & Bold partners & Surgical materials \\
\hline 22 & IBN SINA Pharmaceuticals & Pet food \\
\hline 23 & ANC Medical Device & Packing materials \\
\hline & Meghna Group of Industries & Tube \\
\hline
\end{tabular}

\section{Discussion}

Radiation is actually existed from the very beginning of evolution of life on the earth. It interacts with matter, causes ionization of an atom/molecule; as a result, the physical and biological effects are observed [25]. The most advantageous fact in the radiation process is the absence of any chemical residues. The use of radiation in medicine, industry, agriculture, energy, and other scientific and technological fields has brought tremendous benefits to the 
society, in the clinical sector as well. Radiation is a key tool in the treatment of particular kinds of disease, e.g., cancer [26]. The beneficial impacts are almost similar in other fields.

Compare to the others, gamma irradiation is a fast and fruitful method for sterilization. The high-energy gamma rays (i.e., photons) from Cobalt-60 result in ionization events which can cause desirable effects (e.g., sterilization), in some extent it may cause potential undesirable or unintentional effects (e.g., change in the product's molecules or byproducts) [27]. The penetration capability of photons makes them ideally suited for sterilization of even comparatively thick materials [28]. The photons can cause electron displacement, free radical formation, and consequently the breakage of bond when they pass through a product. The depth of penetration is one of the greatest advantages of gamma irradiation. Depth of photon penetration allows for sterilization of materials of various density levels, this process does not require addition of heat or moisture, well documented for its effectiveness as a sterilization process, and does not produce residuals as are of concern with ethylene oxide sterilization [29].

Food irradiation technology has been recently started in Brazil, China, India, the Republic of Korea, Mexico and Thailand. In Europe, some countries are early supporters of industrial food irradiation, particularly the Netherlands and France [30]. In IRPT, different items of food including pet food, spices, eye drops, surgical gloves etc. are being sterilized regularly to be used in the commercial aspects and in the clinical sectors. BAEC is the pioneering organization in Bangladesh to serve nation through the sterilization of different products in IRPT and in a small scale in the Institute of Food \& Radiation Biology (IFRB) of BAEC [31], and thus increases the national currency by this service. Bangladesh Institute of Nuclear Agriculture (BINA) is a research institute, specialized in agricultural research using nuclear and radiation technology in Mymensingh [32]. The personnel of IRPT are working hard to accelerate the radiation service using existing Cobalt-60 gamma source, this institute is increasing the values of earning year by year (Figure-1). Recently, a development project was sanctioned by the Ministry of Science \& Technology (MoST), Bangladesh on the "Replacement of the existing gamma source at Savar of Bangladesh Atomic Energy Commission" to upgrade and for the incessant continuation of the services at IRPT.

Besides commercial services, in some extent it also gave irradiation services to bone sterilization at the Institute of Tissue Banking \& Biomaterial Research (ITBBR), BAEC, for the environment friendly textile effluent detoxification research etc. [33]. Since this process produces ionization events, it can cause undesirable or unintended effects. So, each product should be sterilized in its final form with irradiation prior to making the final decision to sterilize it [34]. In the radiation application, everyone should consider the probable shortcomings in its various uses. In spite of having some limitations, the irradiation using Cobalt-60 gamma source at IRPT is more popular for their best services. Not only in Bangladesh, it is boosting up the currency from the exported sterilized foods and other materials to produce the life saving medicine.

\section{Conclusion}

For around 12 years IRPT are involved to sterilize foodstuffs and medical products by the gamma irradiation for the commercial purposes. Thus, the general people are getting valuable services and Bangladesh is acquiring a lot of foreign currencies from the exported irradiated foods and spices. However, we all should keep in mind that in some extent gamma irradiation is hazardous, so it is very important to be careful and to ensure the toxicity and quality of the product after radiation. Government, Television, and other media should play the role to broadcast the values of the peaceful uses of gamma radiation throughout the country.

\section{Acknowledgement}

The research was supported by the Special Allocation for Science \& Technology Programme (FY2021-2022), granted by the Ministry of Science \& Technology (MoST), Bangladesh. The project title is 'the construction of biocomposites/biomaterials using chitin and alginate intended to be used for biomedical applications'. Government Order (GO) No. 39.00.0000.009.14.019.21-745; Serial No. 570, Group Serial No. 570 MS.

\section{Conflict of Interest}

There is no conflict of interest among the authors.

\section{References}

[1] Farlex, 2014. Radiation. The free dictionary by Farlex. Farlex, Inc.

[2] Weisstein, E. W., 2014. Radiation. Eric Weisstein's World of Physics: Wolfram Research.

[3] ICRP Publication, 2013. 103- the 2007 recommendations of the international commission on protection. ICRP.

[4] Ng, K. H., 2003. "Non-ionizing radiations-sources, biological effects, emissions and exposures (PDF)." In Proceedings of the International Conference On Non-Ionizing Radiation at Uniten Icnir 2003 Electromagnetic Fields and Our Health.

[5] The Electromagnetic Spectrum, 2015. "Centers for disease control and prevention."

[6] Silindir, M. and Ozer, Y., 2009. "Sterilization methods and the comparison of e-beam sterilization with gamma radiation sterilization." FABAD J. Pharm. Sci., vol. 34, pp. 43-53.

[7] Ionizing Radiation, 2020. Health effects and protective measures. World Health Organization.

[8] Julie, R., 2012. "Ionizing radiation: The good, the bad, and the ugly." The Journal of Investigative Dermatology, vol. 132, pp. 985-993. 
[9] Jacobs, G. P., 1995. "Review of the effects of gamma radiation on pharmaceutical materials." Journal of Biomaterials Applications, vol. 10, pp. 59-96.

[10] Gorna, K. and Gogolewski, S., 2003. "The effect of gamma radiation on molecular stability and mechanical properties of biodegradable polyurethanes for medical applications." Polymer Degradation and Stability, vol. 79, pp. 465-474.

[11] Singh, R., Singh, D., and Singh, A., 2016. "Radiation sterilization of tissue allografts: A review." World J. Radiol., vol. 8, pp. 355-369.

[12] Scheer, K. E. and Maier, B. W., 1963. "On the production of Tc99 $\mathrm{m}$ for medical purposes." NuclearMedizin (in German). vol. 3, pp. 214-7.

[13] Arneodo, F., Di, G. A., and Marpu, P., 2021. "A review of requirements for gamma radiation detection in space using cubesats." Appl. Sci., vol. 11, p. 2659.

[14] Alsharef, S., Alanazi, M., Alharthi, F., Qandil, D., and Qushawy, M., 2020. "Review about radiopharmaceuticals: preparation, radioactivity, and applications." Int. J. App. Pharm., vol. 12, pp. 8-15.

[15] Richard, S. and Dianella, G. H., 2012. Gamma radiation, gamma radiation, Prof. Feriz Adrovic (Ed). USA.

[16] Fain, J., Erramli, H., Miallier, D., Montret, M., and Sanzelle, S., 1985. "Environmental gamma dosimetry using TL dosimeters: Efficiency and absorption calculations." Nuclear Tracks, vol. 10, pp. 639-646.

[17] WHO, 1999. Safety and nutritional adequacy of irradiated food. Geneva: World Health Organization.

[18] Sohn, S. H., Jang, A., Kim, J. K., Song, H. P., Kim, J. H., Lee, M., and Jo, C., 2009. "Reduction of irradiation off-odor and lipid oxidation in ground beef by a-tocopherol addition and the use of a charcoal pack." Radiation Physics and Chemistry, vol. 78, pp. 141-146.

[19] Rima, F. J., Sadakuzzaman, M., Hossain, M. A., Ali, M. S., and Hashem, M. A., 2019. "Effect of gamma irradiation on shelf life and quality of broiler meat." SAARC J. Agric., vol. 17, pp. 149-159.

[20] Harun, M. H., Othman, N., Mohamed, M., Alias, M. S., Nor, K., Umar, K., and Abd, R. M. F., 2019. "Influence of gamma irradiation on the electrical conductivity and dielectric properties of polypyrrole conducting polymer composite films." Polymer, vol. 8, p. 9.

[21] Sandle, T. and Saghee, M. R., 2011. "Some considerations for the implementation of disposable technology and single-use systems in biopharmaceuticals." Journal of Commercial Biotechnology, vol. 17, pp. 319329.

[22] Tezotto, U. J. V., Silva, P. P. M., Kluge, R. A., and Spoto, M. H. F., 2015. "Radiação gama em produtos de origem vegetal." Revista Virtual de Química, vol. 7, pp. 267-277.

[23] Liauw, S. L., Connell, P. P., and Weichselbaum, R. R., 2013. "New paradigms and future challenges in radiation oncology: an update of biological targets and technology." Sci. Transl. Med., vol. 5, p. $173 \mathrm{sr} 2$.

[24] Silindir, M. and Özer, Y., 2012. "The effect of radiation on a variety of pharmaceuticals and materials containing polymers." PDA J. Pharm Sci. and Tech., vol. 66, pp. 184-199.

[25] Bichsel, H. and Schindler, H., 2020. The interaction of radiation with matter. In: Fabjan, c., schopper, $h$. (eds) particle physics reference library. Springer, Cham.

[26] Lawrence, T. and Rosenberg, S., 2008. Cancer: Principles and practice of oncology. Philadelphia, PA: Lippincott Williams and Wilkins.

[27] Randall, H. C. R., Djonov, V., Fellabaum, C., and Volarevic, V., 2018. "Risks of using sterilization by gamma radiation: the other side of the coin." International Journal of Medical Sciences, vol. 15, pp. 274279.

[28] Hasanain, F., Guenther, K., Mullett, W. M., and Craven, E., 2014. "Gamma sterilization of pharmaceuticals-a review of the irradiation of excipients, active pharmaceutical ingredients, and final drug product formulations." PDA J. Pharm. Sci. Technol., vol. 68, pp. 113-137.

[29] Fairand, B. P., 2001. Radiation Sterilization for health care products: $x$-ray. Gamma, and Electron Beam (Crc Press).

[30] Galati, A., Moavero, P., and Crescimanno, M., 2019. "Consumer awareness and acceptance of irradiated foods: the case of Italian consumers." British Food Journal, vol. 121, pp. 1398-1412.

[31] Making Food Safer and Longer-Lasting, 2017. "The daily star."

[32] Cabinet Clears Draft Law For Nuclear Agriculture Institute, 2016. Available: www.Bdnews24.com

[33] Kawasaki, Y., Sotome, S., and Yoshii, T., 2010. "Effects of gamma-ray irradiation on mechanical properties, osteoconductivity, and absorption of porous hydroxyapatite/collagen." Journal of Biomedical Materials Research B: Applied Biomaterials, vol. 92, pp. 161-167.

[34] Kohane, D. S., Tse, J. Y., Yeo, Y., Padera, R., Shubina, M., and Langer, R., 2006. "Biodegradable polymeric microspheres and nanospheres for drug delivery in the peritoneum." Journal of Biomedical Materials Research A, vol. 77, pp. 351-361. 